\title{
Techno-economic viability assessments of greener propulsion technology under potential environmental regulatory policy scenarios
}

\author{
${ }^{\star}$ D.K. Nalianda a , V. Sethi a, Kyprianidis, K.G ${ }^{b}$., R. Singh ${ }^{a}$ \\ a Propulsion Engineering Centre, School of Aerospace, Transport and Manufacturing, Cranfield University, \\ Cranfield, Bedfordshire, MK43 OAL, United Kingdom \\ ${ }^{b}$ Future Energy Centre, Department of Energy, Building and Environment, School of Business, Society and \\ Engineering, Mälardalen University, Box 883, Högskoleplan 1, 72123 Västerås, Sweden
}

\begin{abstract}
Sustainability of the aviation industry, as any other industry, depends on the elasticity of demand for the product and profitability through minimising operating costs. Of paramount importance is assessing and understanding the interdependency and effects of environmentally optimised solutions and emission mitigation policies.

This paper describes the development and application of assessment methodologies to better understand the effects of environmental taxation/ energy policies aimed at environmental pollution reduction and the future potential economic impact they may have on the adaptation of "greener" novel technologies. These studies are undertaken using a Techno-economic Environmental Risk Assessment approach. The methodology demonstrated allows the assessment of the economic viability of new technologies compared to conventional technologies, for various emission taxation and fuel price scenarios. It considers relative increases in acquisition price and maintenance costs.
\end{abstract}

A study undertaken as a 'proof of concept' compares a Counter Rotating Open Rotor aircraft with a conventional aircraft for short range. It indicates that at current fuel price and with no carbon taxation, a highly fuel efficient technology, such as the one considered, could be rendered economically unviable.

The work goes on to demonstrate that in comparison to the conventional aircraft, any economic benefits that may be accrued from improvement in fuel consumption through such a technology, may well be negated through increases in acquisition price and maintenance costs. The work further demonstrates that if policy makers want to direct the industry towards greener propulsion solution, then an increase in $\mathrm{CO}_{2}$ emission taxation may be appropriate.

\section{Keywords}

Environmental taxation, Assessment methodology, Investment cost

\section{Nomenclature}

BAU

Business As Usual (scenario)

BET

Baseline Emission Tax (scenario)

CROR

Counter Rotating Open Rotor

DOC

Direct Operating Cost

ETRW

Energy To Revenue Work Ratio

g acceleration due to gravity $\left(9.81 \mathrm{~m} / \mathrm{s}^{2}\right)$

HEA

High Environmental Awareness (scenario)

HEA_HFP

High Environmental Awareness and High Fuel Price (scenario)

\footnotetext{
* Corresponding author. Tel.: +44 1234754742,

E-mail address: devaiah.nalianda@cranfield.ac.uk
} 


\begin{tabular}{ll} 
IRR & Internal Rate of Return \\
JT & Engine designation \\
LCV & Lower Calorific Value \\
LTO & Landing and Takeoff \\
MD & Airplane designation \\
Mf & Mass of mission fuel (kg) \\
MLW & Maximum Landing Weight (kg) \\
Mpl & Maximum payload mass of the aircraft (kg) \\
MTOW & Maximum take-off weight (kg) \\
MZFW & Maximum Zero Fuel Weight (kg) \\
NASA & National Aeronautics and Space Administration \\
NPV & Net Present Value \\
OEW & Operating Empty Weight (kg) \\
PEA & Progressive Environmental Awareness (scenario) \\
PFEE & Payload Fuel Energy Efficiency \\
R & Great circle distance (km) \\
SFC & Specific Fuel Consumption ( $/(\mathrm{kN}$ •s)) \\
TERA & Techno-economic Environmental Risk Assessments \\
TF & Turbo Fan \\
UDF & Un-Ducted Fan \\
WACC & Weighted Average Cost of Capital (\%) \\
\hline
\end{tabular}

\section{Introduction}

The aviation sector has played a significant role in shaping the world into what it is today. The rapid growth of global economies and the corresponding sharp rise in the number of people now wanting to travel on business and for pleasure, has largely been responsible for the development of this industry. However the significantly large increase in air passengers over the years has led to an increase in air traffic and a corresponding rise in fuel consumption, aviation emissions and noise.

Over the years, the industry has consistently invested in improving technology and introducing it into commercial applications, with the aim to always remain profitable. With fuel expenses being a significant part of an airline's operating cost, the core focus of technology development in the past has been to constantly improve fuel economy. This has been accomplished whilst actively striving to lower costs (production and maintenance) reduce weight, maintain Landing and Take-Off (LTO) cycle noise and $\mathrm{NO}_{x}$ within certification limits and improve safety and reliability. However, with aviation emissions now becoming a cause for growing global concern and various emission mitigation policies coming into focus, the industry is actively pursuing even "greener" and quieter solutions for the future. 
Sustainability of the aviation industry, as any other industry, depends on the elasticity of demand for the product and profitability through minimising operating costs. Apart from other factors, this profitability is directly affected by technology infusion, be it aimed towards any of the global objectives, which include reducing fuel burn, environmental emissions or noise. Therefore assessing and understanding the interdependency and effects of future technology and emission mitigation policies is paramount.

A significant insight into this area has been provided by research within the Omega project (Dray et al., 2009, Dray and Morrell, 2009). The work assessed the effect that mitigation policies and technology options may have on the potential of reducing emissions, on a regional and global scale.

Another aspect of this field of study, dealt with aircraft conceptual design optimised for environmental performance (Henderson et al., 2012). The work utilised numerical optimisation techniques in aircraft design on multiple aircraft to investigate the tradeoffs between the various environmental performance metrics and direct operating costs. Padulo (2009) presented a novel and computationally efficient method for carrying out civil aircraft conceptual design optimisation under certainty

Research undertaken by Kirby and Mavris (2001), dealt with forecasting and selecting future technologies and proposed a methodology to select an ideal combination amongst a set of emerging concepts. The aim of the research was to select the technologies based on maximum predicted economic profitability and hence the maximum return on research and development investments.

All the research reviewed and referenced have used elaborate model integration frameworks and tools to provide interesting perspectives on the interdependencies of technology solutions and emission mitigation initiatives. However, an important literature gap can be identified: all of the established frameworks fail to specifically bridge the chasm between research/development of advanced and innovative environmental friendly technology and final implementation.

The primary objective of the current work is to specifically assess economic viability and the boundaries within which a particular energy efficiency improvement technology is financially sustainable. In more detail, the work introduces an integrated methodology that may be used to assess economic viability by demonstrating the sensitivity of operating cost to uncertain acquisition prices and maintenance costs of futuristic technology.

The focus of the work is to combine energy efficiency technology assessments with concepts of Net Present Value (NPV) and Internal Rate of Return (IRR) within an investment cost analysis approach. The study will first utilise and further develop a Techno-economic Environmental Risk Analysis (TERA) framework to produce a set of assessments (Kyprianidis, et al., 2008; Pascovici, D.S, 2008; Kyprianidis, 2010). These assessments will compare a novel technology with competing conventional solutions and establish its benefits in terms of performance and energy efficiency. These studies are undertaken for various emission taxation and fuel price scenarios to further establish if the observed efficiency may be translated to improvements in operating cost.

The aim is to answer important questions from a policymaker's or airline operator's perspective, primarily on the issue of whether the technology under consideration can translate fuel efficiency to operating profits. Within this process, it is imperative to establish if the perceived advantages are sufficient to supersede what's already on the market and thus offset a higher acquisition price and complexity of aircraft.

In essence, the research question to be answered is:

What taxation or fuel price scenario will establish economic viability and actually justify a technology shift from a conventional solution, given a particular acquisition and maintenance cost change? 
In the last decade with the price of fuel rapidly rising and $\mathrm{CO}_{2}$ emissions from aviation being driven into focus, a renewed interest has been shown by the industry in rediscovering the benefits of fuel saving concepts. The proof of concept of the approach is demonstrated, by assessing the Counter Rotating Open Rotor (CROR) concept as a competitive technology solution, against the conventional high bypass turbofan.

\section{Methodology}

\section{$2.1 \quad$ Technical approach/ TERA framework}

Techno-economic Environmental Risk Analysis (TERA) essentially comprises a framework of mathematical models to simulate the performance of a single or a set of technologies. The framework allows an increased visibility of risks, whilst enabling the user to compare and rank competing schemes on a formal and consistent basis, so that investment resources may be allocated efficiently (Goulos, et al., 2010; Najafi Saatlou, et al., 2014; Doulgeris, G., et.al. 2012).

The framework (Fig. 1) is modular in structure and consists of a set of core models, which allow simulation of detailed power-plant systems, with component physics-based mathematical models. The core models can be further coupled with a wide range of environment, economic and risk models. The assessments are conducted on a system and mission level and may be used to deliver an insight into the relative risks and benefits of promising but uncertain concepts, at lower TRLs (Technology Readiness Level) of development.

Technology Readiness Levels (TRL) are a type of classification system used to assess the maturity level of a particular technology (NASA, 2014). Each technology project is evaluated against the parameters for each technology level and is then assigned a TRL rating based on the projects progress. There are nine technology readiness levels. TRL 1 is the lowest and TRL 9 is the highest.

The TERA utilising this classification system offers an independent and consistent evaluation procedure to assess the maturity of evolving technologies during their development process and additionally allows comparative studies of complex systems, encompassing local and global conditions.

TERA has been used extensively in the past to conduct design space exploration and trade-off studies, parameter sensitivity analysis, asset management and multi-disciplinary optimisation (Kyprianidis, et al., 2011; Kyprianidis, et al., 2014; Xu, et al., 2013; Najafi Saatlou, et al., 2014; Camilleri et al., 2014). Frameworks that utilise a similar approach to TERA have also been used successfully by other researchers in the field for novel technology assessments (Marinai,L., et.al. 2004; Alexiou, et al., 2012, Hu, et al., 2012).

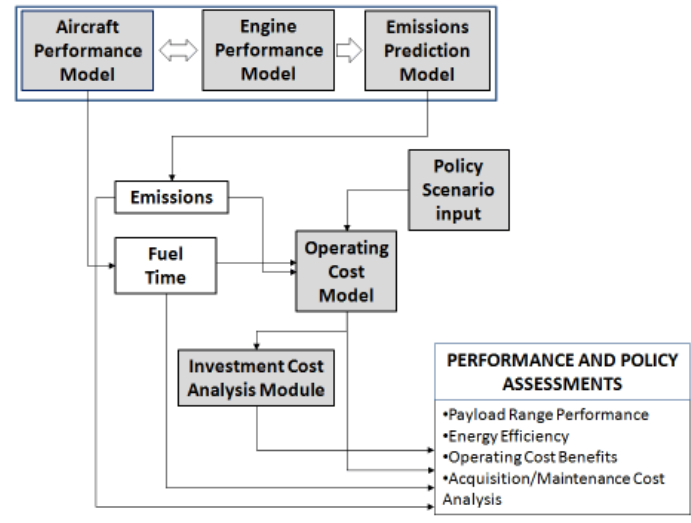

Fig. 1 Schematic of TERA framework 
This study utilises a TERA model framework to produce a set of performance and policy assessments in terms of payload range performance, energy efficiency, relative operating cost benefits and acquisition/maintenance cost analysis.

The analysis of a novel technology begins by using the aircraft and engine performance models to establish an aircraft's payload-range performance. This provides the assessor with a performance summary giving an estimation of its overall performance characteristics (Eshelby, 2009). The performance and payload range capability is then compared with an aircraft with a single or a set of competing conventional technologies.

For a transportation system to be profitable it has to be energy efficient. Therefore, the optimal utilisation of available energy is of prime importance. Various efficiency metrics have been used to assess energy efficiency of transportation modes. One of these metrics is the Energy To Revenue Work (ETRW) ratio and quantifies the energy liberated during a flight with respect to the work done for which a revenue may be earned. The metric has been utilised as a key indicator in the assessment of energy efficiency of aircraft (Poll, 2009). It was found to be particularly useful as it can be used to assess a technology purely from an energy efficiency perspective, whilst taking into account the useful work done in terms of its revenue earning potential. The minimum value of this metric is considered as the optimal value in terms of energy efficiency.

$E T R W=\left(M_{f} \cdot L C V\right) /\left(M_{p l} \cdot g \cdot R\right)$

The next stage of the assessment utilises the ETRW metric to map the energy efficiency of a technology. This is done in comparison with the competing technologies, across its range of payloadrange operations. This analysis, whilst providing a broader perspective on the operational capability of aircraft in comparison to various other solutions, also enables identifying the solution against which the economic viability of the combination of aircraft and route may be assessed.

The methodology then progresses from the assessment of performance and energy efficiency of the technologies under comparison to establishing the operating cost benefits of the novel technology as opposed to the selected conventional solution. This is undertaken for a set of missions that effectively represent the aircraft in terms of payload and range.

The benefit in operating cost is established in terms of the relative changes and the overall increase in operating costs between the two technologies, for a series of emission tax and fuel price scenarios.

The final phase of the methodology uses the investment cost analysis module to produce the DOC (Direct Operating Cost) and IRR contour plots. These plots, for a selected set of missions, illustrate the effect of the relative changes in acquisition price and maintenance costs, on operating cost using the concepts of IRR and NPV.

The assessments produced using this approach aim to provide an assessor with a clearer visibility of the operational and economic viability of utilising a novel technology, through a performance and cost benefit analysis.

\subsection{A description of TERA modelling modules}

The section provides a brief overview of the TERA modelling suite. A detailed analysis and verification of the models has been conducted and is presented by Nalianda, D.K.(2012).

\subsubsection{Engine performance modelling}

The engine models are simulated using an in-house gas turbine performance simulation and diagnostics software developed by Cranfield University called TURBOMATCH (Macmillan 1974). 
Engine performance modelling was primarily based on the use of generic compressor and turbine characteristics as well as empirical correlations (Walsh and Fletcher, 1998). Component characteristics were scaled based on the procedure outlined by Macmillan (1974) at the hot-day top of climb condition; nozzle throat areas were also determined at the same operating condition. This particular choice for the reference condition is consistent with recent modelling work presented by Alexiou, et al (2012). Off-design matching was achieved using the generic matching procedure presented by Fawke and Saravanamuttoo (1971).

All thermodynamic calculations were based on the assumption of an ideal gas (i.e., variable specific heat capacity); therefore, the main thermodynamic equation used was the Gibbs equation. The HPT Thermal Barrier Coating (TBC) average external surface blade metal temperature and corresponding cooling flows have been modelled using the simplified approach presented by Kurzke (2003). In order to simulate the effects of the UDF propulsion system, as will be explained in the later part of this study, a propeller module was developed within the engine performance tool. This propeller module was based on information available for a UDF propulsion system designed, fabricated and tested for Mach 0.72 configuration (Hager, 1987). A schematic of the engine performance model is illustrated in Fig. 2.

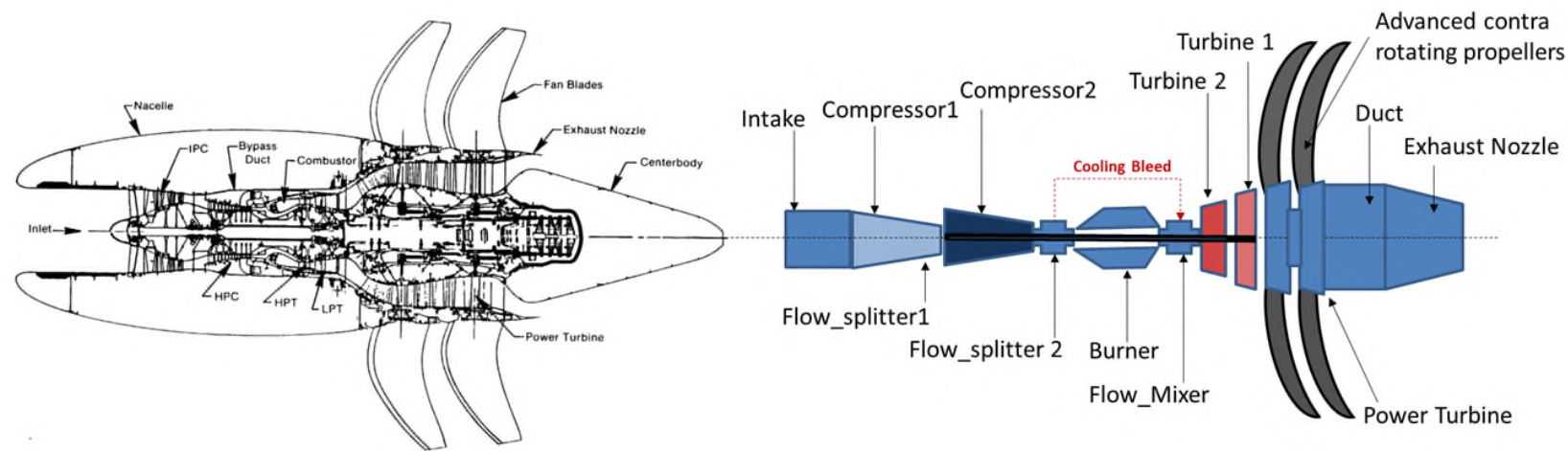

Fig. 2 Performance model Schematic- UDF propulsion system (GE Aircraft Engines, 1987)

\subsubsection{Aircraft performance modelling}

The aircraft performance is modelled and simulated using an in-house tool, HERMES (Laskaridis, P., 2004). The tool has been used previously within the TERA framework to simulate and assess the potential performance and benefits of adopting new technologies and concepts (Bellocq, et al., 2010; Kyprianidis, et al., 2011; Giannakakis, 2013). The model is capable of predicting aerodynamic characteristics given the required inputs for an aircraft, and is combined with Turbomatch in order to calculate the overall performance as an integrated aircraft/engine system.

The aircraft dimensions modelling was based on Jenkinson (1999) while the aerodynamics were modeled according to Jenkinson (1999) and ESDU (1997). The aircraft performance modelling was based on Jenkinson (1999) and Laskaridis (2004). In more detail, the tool models the aircraft as a point-mass and equates the rate of work done by forces acting on the aircraft to the rate of increase in potential and kinetic energy (Total-Energy Model). It simulates complete trajectories and missions and produces as outputs, various engine performance parameters during the flight schedule (i.e. take-off, climb, cruise, descent and landing) such as SFC, combustor outlet temperature and compressor surge margins.

A propulsion system integration module has also been integrated. It is used for optimising nacelle geometry and engine position based on power plant cycle optimisation requirements (Sibilli, T., 2012). Finally, the integrated tool has been validated against published data (Laskaridis, P., 2004). 


\subsubsection{Operating cost model}

Direct Operating Cost for economic analysis is frequently used as the measure of merit to evaluate aircraft in design trade-off studies. A simple operating cost model has been incorporated within the framework for this study and considers only the Direct Operating Cost (DOC). It is broadly based on the methodology as illustrated in figure 3.

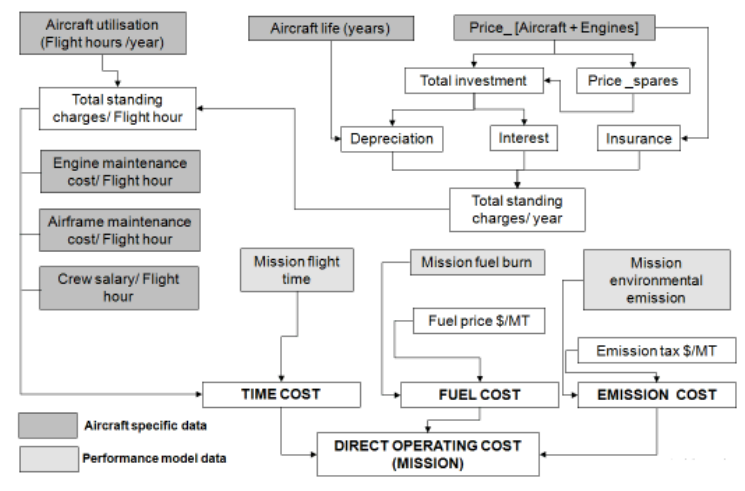

Fig. 3 Schematic of Direct Operating Cost Model

The operating cost within the model is further separated into time related costs, fuel related costs and emissions related costs.

2.2.3.1 Time related costs: These costs include the following:

- $\quad$ Airframe and engine maintenance charges: Every conventional aircraft is assumed to have a certain average utilisation in terms of number of flying hours, flight cycles and a ratio of flight hours to flight cycles. Based on the periodicity of the maintenance routines and the annual utilisation, a cost of maintenance per hour is established. Referenced literature (Aircraft Commerce, 2010) was found to have published open source data for these costs.

- $\quad$ Flight and cabin crew salaries

- $\quad$ Standing/ownership charges: The standing / ownership charges are not directly linked to a specific mission of the aircraft, but depend on the type and annual utilisation of the aircraft. These charges are calculated by the operating cost model as a part of the direct operating cost when an aircraft is assumed to be procured through outright purchase, as opposed to being leased (Pascovici, et al., 2008; Pascovici, 2008). It is therefore based on depreciation of the capital investment, interest on capital employed and insurance. The model also calculates the annual charges, and based on the annual utilisation, divides these costs for each mission.

2.2.3.2 Fuel dependant costs: These costs reflect the total amount of fuel consumed during the flight.

2.2.3.3 Emission dependant costs: The model currently calculates the emission costs for a flight based on the taxation scenario and the total amount of emissions $\left(\mathrm{CO}_{2}\right)$ generated.

The operating cost model enables the calculation of the relative change in operating cost for competing technologies, given a particular fuel price and a hypothetical emission taxation scenario. As this work is focussed on assessments to compare novel technology and competing conventional solutions, certain assumptions for a conventional aircraft are made within the operating cost model, based on public domain data (Jenkinson et al., 1999; Aircraft Commerce, 2010).

For the novel technology, the input for the model is set as a percentage of the data available for a conventional aircraft. The fuel consumed, emissions generated and time taken for the mission is obtained from aircraft and engine performance and emission prediction models, for each of the individual technologies being considered. 
Based on these calculations and, for a range of missions flown, a comparative assessment is made of the operating costs for the technologies under consideration.

\subsubsection{Investment cost analysis module}

The investment cost analysis module examines the effect of increased acquisition and maintenance costs on the relative change in direct operating cost. A typical contour plot is as illustrated in Fig 5.

The contour plots are essentially two dimensional plots that show one dimensional curves, on which a plotted quantity $Z$ is a constant.

For the two technologies being compared, each point on a contour plot signifies a solution's operating cost $Z$, with its position as a function of $\mathrm{X}, \mathrm{Y}$, where:

$X=\%$ increase in Maintenance Cost

$Y=\%$ increase in Acquisition Cost

$Z=\%$ change in Direct Operating Cost

Where Direct Operating cost is a function of the flight block time, flight fuel burn, emissions $\left(\mathrm{CO}_{2}\right)$, acquisition cost and maintenance costs, as discussed in the previous section.

At the datum point (bottom left corner), the relative benefit in direct operating cost is calculated with the assumption that the novel technology has the same acquisition and maintenance costs with the baseline one, and the change in operating cost is primarily due to the difference in block fuel burn, block time and environmental emissions. However as the relative acquisition and maintenance costs increase, there is a corresponding decrease in relative improvement in operating cost which eventually diminishes to zero (as indicated in Fig. 4).

The investment cost analysis module is then used to analyse if the increase in acquisition cost or/and maintenance cost, and consequently to determine if the diminishing operating cost benefit is still viable economically. This is achieved by using the concept of Net Present Value (NPV) and Internal Rate of Return (IRR) (Raymer, 2006).

For a combination of increase in acquisition and maintenance cost, assuming a discount rate, the yearly profit from the difference in operating costs for the two competing technologies is converted to the NPV. The NPV of each year, over the operational life of the aircraft, assumed as the payback period, is then summed up. For the investment to be profitable the sum of the NPV estimates over the life of the aircraft must be greater than the difference in acquisition cost incurred in procuring the new technology.

The IRR of a project is the discount rate at which the NPV is equal to zero and is a measure to evaluate if a project is economically viable. The module iteratively calculates the IRR of the investment by solving for the discount factor at which the NPV equals the difference in acquisition cost. Fig. 4 indicates the methodology used to calculate the IRR.

For a specified minimum required rate of return and based on an assumed Weighted Average Cost of Capital (WACC) on the investment, the module establishes the non-feasible investment region. It essentially calculates the region on the contour plot (Fig.5) for which the IRR falls below the WACC and indicates it as the sub-optimal (non-feasible) shaded region.

For any particular point on the contour, the NPV/IRR is calculated based on the following assumptions: 
- Profit generated per year is calculated on a relative basis, from the difference in operating costs, derived from the percentage change in direct operating costs for the two competing technologies. This profit is then assumed constant through the lifespan of the aircraft

- The discount rate or interest rates used to calculate the NPV is constant throughout the lifetime of the annuity

- The competing solutions have the same economic life in terms of years

Therefore for a mission of a particular range, and for a given fuel price and emission taxation scenario, each contour plot created provides information on the datum operating cost benefit and then illustrates the effect of increased acquisition and maintenance costs on the economic viability of the technology.

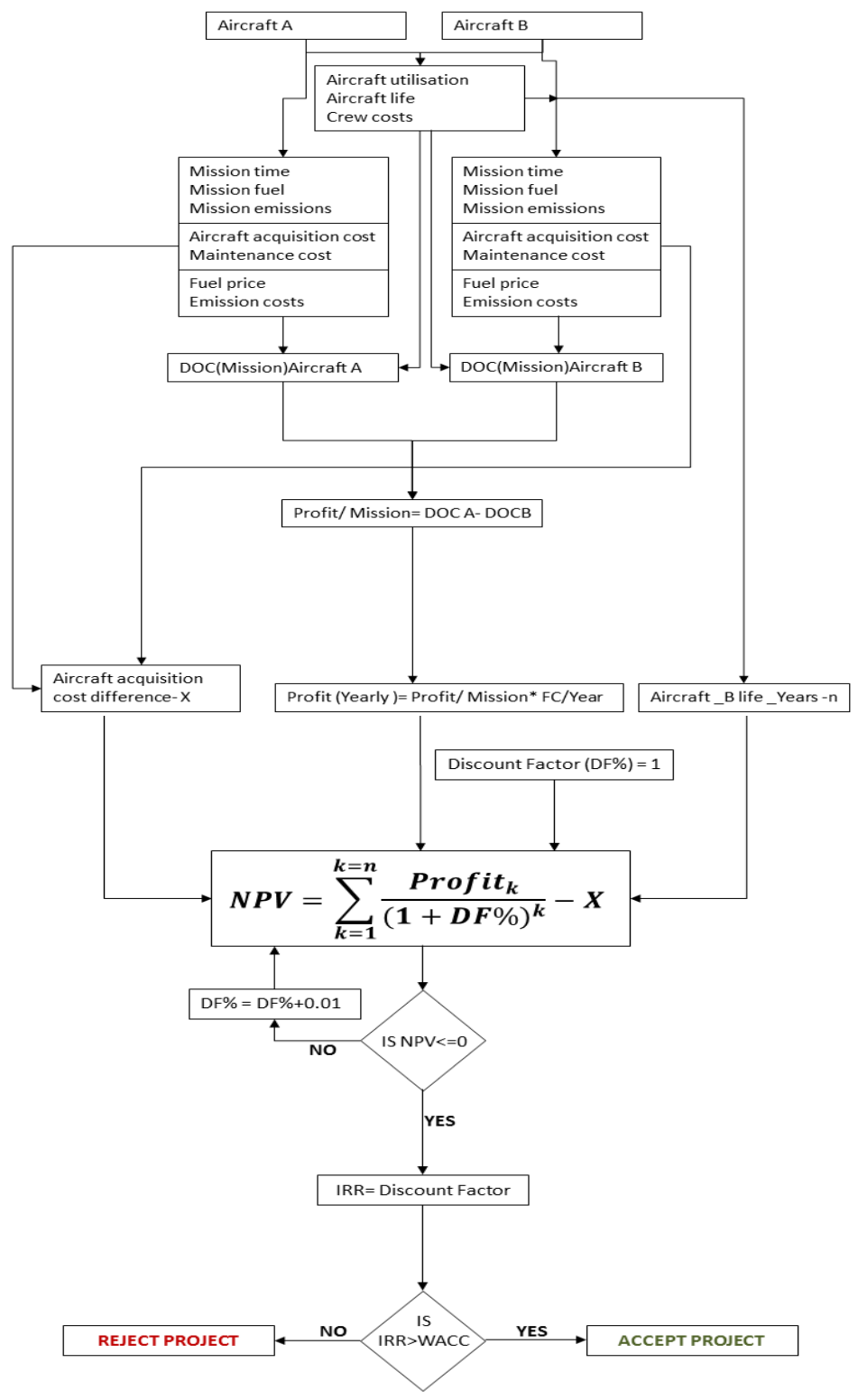

Fig. 4 Methodology used to calculate Internal Rate of Return (IRR) (Nalianda, 2012). 


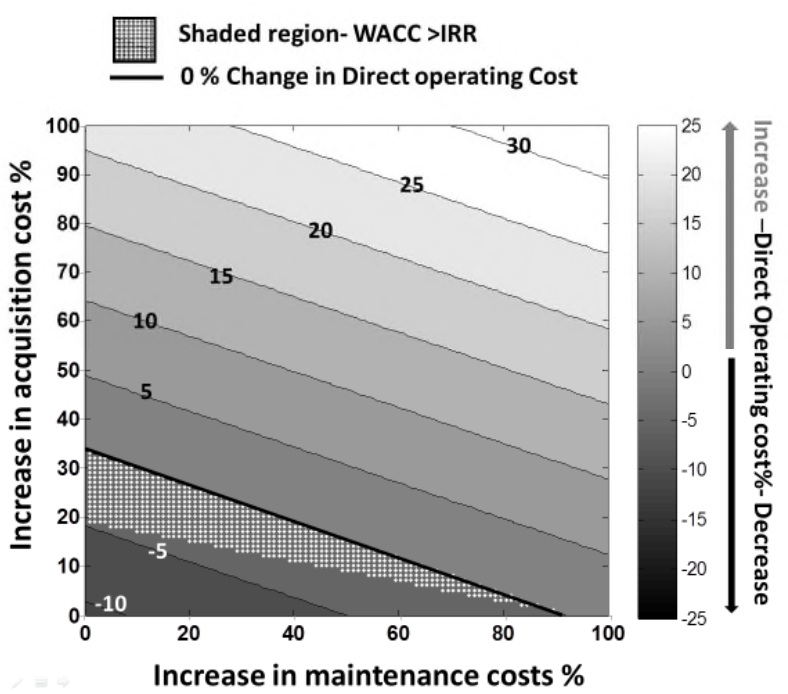

Fig. 5 Illustrative example of investment cost analysis contour

\subsection{Case Study}

The transition from turbojets to turbofans in the late 1960s was specifically aimed at reducing fuel burn and LTO cycle $\mathrm{NO}_{x}$ emissions and noise, whilst improving safety and reliability. The oil embargo in the 1960s and the instability in Middle East in the 1970s drove the oil prices to new heights (Bowles and Dawson, 1998). This resulted in airlines around the world paying the penalty through staggering losses. Within the aviation industry, these events primarily led to the focused research and development that was aimed at revolutionary reductions in fuel burn, in comparison to the high bypass turbofan. In the late 1970s, this research led to the genesis of the revolutionary concept of counter rotating open rotors (Reid, 1998).

Owing to its ultra-high bypass ratio, and hence a very high propulsive efficiency, the CROR concept implemented as the Un-Ducted Fan (UDF), was stated to provide an SFC of $25-27 \%$ lower than that of the best turbofan engine going into service at the time (Mair and Birdsall, 1996). However, due to low fuel prices prevailing in the late 1980s, complexity in design and strong competition from conventional and technically settled high bypass ratio engines, the concept never reached commercial application (Flight International(12 June), 2007).

With fuel prices on the rise in the last decade and aviation a part of the European Union's Emission Trading Scheme from 2012, the CROR technology is being actively pursued by the industry as a possible future solution.

The approach described in this paper is demonstrated through a proof of concept study to assess the potential of the CROR Technology, as a technology solution to compete with the conventional high bypass ratio turbofan technology. This case study aims to illustrate the wealth of useful insights provided by the proposed techno-economic approach, rather than to comprehensively assess purely the technical aspects of the CROR concept. For a detailed technical analysis of the open rotor concepts the reader is referred to (Vera-Morales, et al., 2008; Belocq, et al, 2010; Larsson, et al., 2011; Guynn, et al., 2011)

In accordance with the methodology discussed earlier, the analysis begins with the payload - range and energy efficiency assessments of the novel technology. These performance assessments are compared with those of conventional short-medium range aircraft. These include a short-medium range turbofan (TF) aircraft (160-180 passengers) and a short range turboprop aircraft (68-72 passengers). 
Based on a comparison of payload range and energy efficiency of these solutions, a conventional solution is then selected as a baseline to analyse the relative direct operating cost and investment cost benefits of the novel technology.

All aircraft missions simulated in this study for the novel and conventional aircraft were assumed to follow international flight rules as stipulated by part 121 of the Federal Air Regulations and include standard assumptions on fuel reserves, diversion fuel and contingency fuel. The aircraft and engine performance models are validated against public domain data and achieve good accuracies in payload-range capability.

\subsection{Aircraft/Engine Modelling}

Limited design information is available in the public domain on the actual implementation of the CROR concept on a commercial aircraft. McDonnell Douglas in the 1980s used a derivative approach and designed a new variant of the existing MD80 aircraft, by replacing the JT8D engines with the UDF. In this work the technology was modelled in a similar approach; i.e. the aircraft and engine performance model were based on the aerodynamic and performance characteristics of the MD-80 aircraft and NASA's Un-Ducted Fan (UDF) engine respectively.

The study currently does not consider any optimisation of the airframe and propulsion system design. Hence it assumes the basic airframe and pylon weight/dimensions and aircraft/ propulsion system limitation parameters remain unchanged. These, therefore, include the aircraft mass and balance (comprising maximum take-off weight (MTOW), maximum landing weight (MLW), maximum zero fuel weight (MZFW), operating empty weight (OEW), fuel capacity, max payload), number of passengers, mean centre of gravity position, maximum operational altitude, environmental envelope and aircraft dimensions (wing span, overall length, tail height, wing span, reference wing surface area).

The aircraft and engine model are developed using Cranfield University's in-house aircraft performance (Hermes) and engine performance (Turbomatch) tools respectively. The UDF engine simulation performance trends and design parameters were validated and verified against data available in the reference (Hager, 1987) and were found to be in good agreement (Nalianda, D.K., 2012). The performance of the aircraft, with the propulsion system integrated, is verified against the actual payload-range chart of the MD80 to establish the payload range capability of the modelled aircraft (Fig. 6) (Boeing, 1990).

All missions simulated for the aircraft follow typical take-off, initial climb, approach configurations and typical speed-schedules for climb, cruise and descent. The cruise segment of the mission was simulated at a fixed altitude of $35000 \mathrm{ft}$. and at a design cruise speed of $0.72 \mathrm{Mach}$. It may be noted that even though the aircraft with conventional turbofan has a typical cruise speed of 0.76 Mach at $35000 \mathrm{ft}$. (Boeing, 1995), a speed of 0.72 was selected as it was the design speed of the propeller modelled. Block fuel and time are calculated by adding a standard 15 minutes of taxiing time and equivalent fuel to mission fuel and time respectively. All missions simulated were assumed to carry standard reserves which included diversion of $200 \mathrm{~nm}$, hold at $5000 \mathrm{ft}$. for 20 minutes and $5 \%$ of block fuel.

As expected, due to the higher propulsive efficiency, the payload range chart in Fig. 6 illustrates that with the use of the CROR concept the aircraft's range capability improves, which is further illustrated by three key points on the payload range chart:

-The range with maximum payload (point B) has increased by $67 \%$ (point B').

-The range flown with maximum fuel and associated payload to maintain maximum take-off weight (point C) has increased by $57 \%$ (point C').

-The ferry range (point $D$ ) has increased by $43 \%$ ( point $\left.D^{\prime}\right)$. 


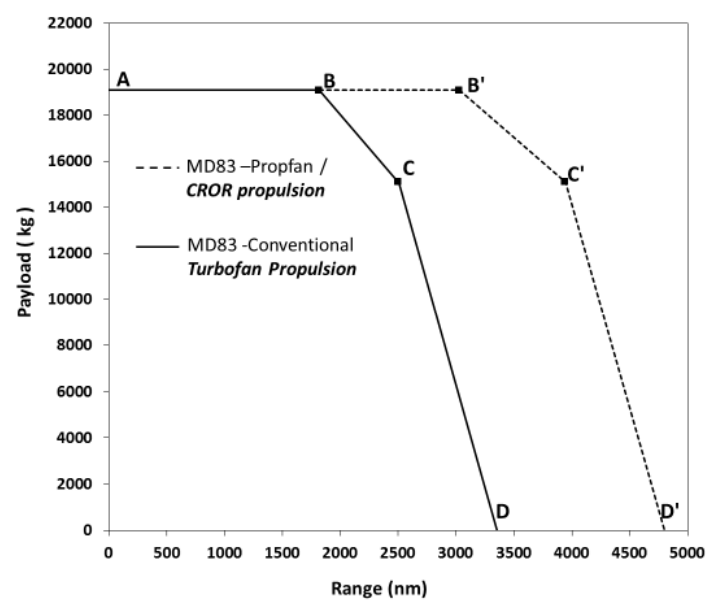

Fig. 6 Payload Chart for MD80 aircraft with conventional propulsion and CROR propulsion

The engine/aircraft modelling results presented in Fig. 6 demonstrate the effect of improved fuel burn performance through application of the open rotor technology through extended range capability. Due to increased propulsive efficiency of open rotor technology such an observation may be considered typical of such a conversion. Consequently, the created models can therefore be considered as appropriate for use within the proposed framework to conduct the techno-economic assessments.

\subsection{Payload range performance and energy efficiency}

The plots in Figs. 7 and 8 demonstrate the payload-range performance and energy efficiency of different technological solutions. The modelling of the payload range performance of conventional short to medium range turbofan aircraft has been undertaken using the engine/aircraft performance simulation models described earlier and is based on public domain data available for a typical Boeing 737-800 aircraft powered by CFM56-7B27 turbofan engines (Boeing, 2006). The payload range performance and ETRW ratios (indicated by triangular marker) of the short range turbo prop aircraft are based on public domain data available for the ATR $42 / 72$ aircraft. (ATR, 2009). The plots enable the identification of the solution with the highest energy efficiency, among a set of competing options for missions at their individual maximum payloads.

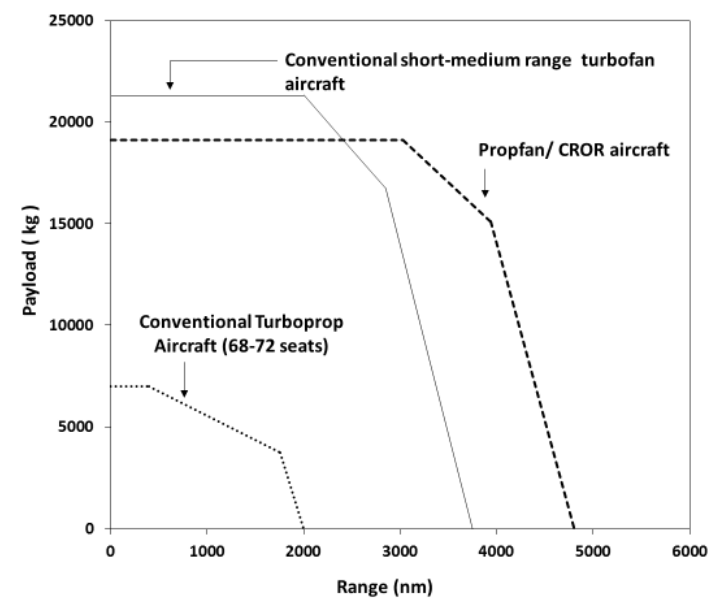

Fig. 7 Payload range capability of aircraft with conventional propulsion and CROR propulsion 


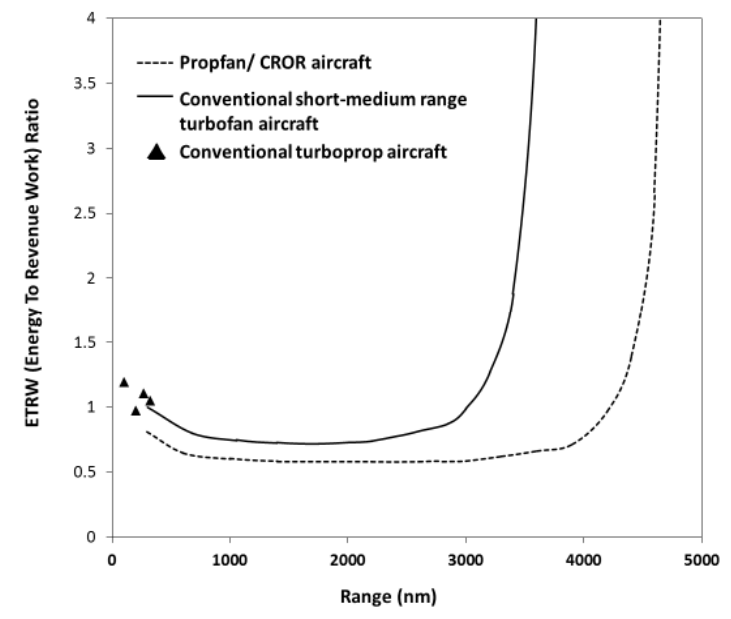

Fig. 8 Energy efficiency curves of aircraft with conventional propulsion and CROR propulsion

The assessments from the plots are summarised as follows:

- The aircraft are observed to be less energy efficient at very short ranges, this is attributed to the fact that significant part of the weight carried on aircraft over short distances includes the weight of the reserve fuel, which reduces the overall energy efficiency.

- The CROR aircraft is able to achieve longer ranges at equivalent payloads than all the aircraft under comparison.

- For the particular payload-range requirements associated for a short to medium range aircraft, the CROR aircraft is found to have a lower energy to revenue work ratio, of up to $15-22 \%$ in comparison to the single aisle narrow body aircraft across its representative range $(500-2500 \mathrm{Nmi})$ capability, and hence is considered to be a more energy efficient solution than the conventional aircraft.

\subsection{Operating cost analysis}

The economic performance for both the novel and conventional aircraft/engine combinations is illustrated in Fig. 10. The results are based on a set of trajectories representing typical missions in terms of range and payloads (Fig. 9) assuming a load factor of $100 \%$. It is opined that such an assumption for the air transport industry may be considered to be extremely optimistic. However, since the study is a comparative assessment of two technologies, such a load factor assumption may be considered acceptable.

A summary of the block fuel burn and time for the different missions of the conventional aircraft are given in Table 1. The two last columns show the relative change in fuel consumption and block time when the CROR concept is implemented. It may be noted that for the operating cost analysis, the cruising speeds selected for the missions by the CROR aircraft and the conventional aircraft have been selected based on optimal speed for maximum specific air range, and hence set at Mach 0.72 and Mach 0.78 respectively.

The operating cost is calculated for five different fuel price and emission $\left(\mathrm{CO}_{2}\right)$ taxation scenarios as indicated in Table 2. The first scenario is the BAU (Business As Usual) scenario reflecting the current fuel price and no taxation on $\mathrm{CO}_{2}$ emissions. The next three scenarios (BET, PEA and HEA) reflect the current levels of fuel pricing and an increasing level of $\mathrm{CO}_{2}$ taxation, while the HEA_HFP scenario reflects a fuel price that has doubled, along with a high $\mathrm{CO}_{2}$ taxation level. It may be noted that all the scenarios selected in the work presented have been chosen for illustrative purposes. Scenarios from models such as MERGE and MiniCam (IPCC, 2007) may also be appropriate for such assessments. 
The carbon taxation levels and fuel prices used in the scenarios have been selected in order to examine the progressive effects of increasing taxation and fuel prices to very high levels for the case under consideration.

The fuel burn and block time are then used to calculate the operating cost for the missions for both the technologies and a relative change in operating cost is estimated.

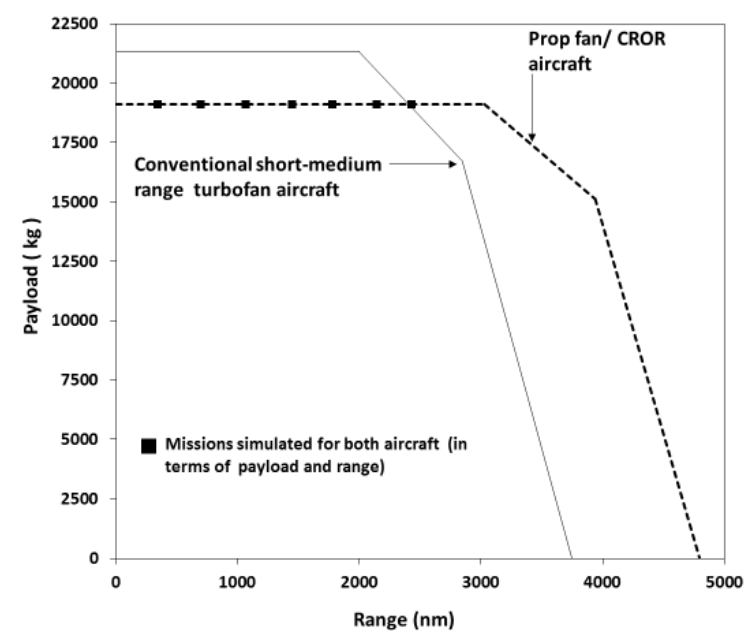

Fig. 9 Representative missions selected for performance comparison of conventional TF aircraft and CROR aircraft

Fig. 10 shows the relative benefits in fuel burn and operational costs, from using the CROR concept, for the five scenarios and the set of representative missions discussed earlier. The fuel burn reduction ranges from $25.3 \%$ to $29 \%$, with the best fuel efficiency improvement being achieved for the shorter ranges. This is attributed to sub-optimal performance for a greater part of the mission for shorter ranges. However as the range of the mission increases, the lower equivalent cruise speed for the CROR aircraft (Mach 0.72) in comparison with that for the conventional TF aircraft (Mach 0.78) will penalise its overall comparative performance. More specifically, as the trip range increases the time penalty of the lowered cruise speed is manifested by lowered reductions in trip fuel consumption. The predicted fuel savings and trends are similar to the ones presented in several studies sponsored by NASA in the 70s and 80s (Jeracki et al., 1979; Stefko et al., 1983).

\begin{tabular}{|r|c|l|l|l|l|}
\hline Cases & Range Nmi & $\begin{array}{l}\text { Block Fuel } \\
\text { burnt-Kg } \\
\text { (Conventional } \\
\text { TF aircraft) }\end{array}$ & $\begin{array}{l}\text { Block Time - } \\
\text { min } \\
\text { (Conventional } \\
\text { TF aircraft) }\end{array}$ & $\begin{array}{l}\text { \% Improvement } \\
\text { in Fuel } \\
\text { Consumption } \\
\text { (CROR aircraft) }\end{array}$ & $\begin{array}{l}\text { \% Increase in } \\
\text { Block Time } \\
\text { (CROR } \\
\text { aircraft) }\end{array}$ \\
\hline \multicolumn{6}{|c|}{ Maximum Payload Missions (19108 Kg- Max payload for CROR aircraft) } \\
\hline 1 & 344 & 2902 & 63 & 29.0 & 1.9 \\
\hline 2 & 697 & 4982 & 111 & 28.6 & 3.6 \\
\hline 3 & 1068 & 7130 & 161 & 27.4 & 5.0 \\
\hline 4 & 1450 & 9385 & 212 & 26.6 & 5.6 \\
\hline 5 & 1783 & 11390 & 257 & 26.1 & 6.2 \\
\hline 6 & 2148 & 13633 & 306 & 25.6 & 6.5 \\
\hline 7 & 2433 & 15420 & 344 & 25.3 & 6.5 \\
\hline
\end{tabular}

Table 1. Block fuel burn and time for representative missions 


\begin{tabular}{|c|l|c|c|}
\hline & Scenario & Fuel Price (\$/MT) & $\mathbf{C O}_{2}$ (Tax \$/MT) \\
\hline$\Delta$ & Business As Usual(BAU) & 1062 & 0 \\
\hline $\mathbf{O}$ & $\begin{array}{l}\text { Baseline Environmental } \\
\text { Taxation (BET) }\end{array}$ & 1062 & 25 \\
\hline $\boldsymbol{*}$ & $\begin{array}{l}\text { Progressive Environmental } \\
\text { Awareness(PEA) }\end{array}$ & 1062 & 250 \\
\hline$\times$ & $\begin{array}{l}\text { High Environmental } \\
\text { Awareness(HEA) }\end{array}$ & 1062 & 500 \\
\hline $\mathbf{\Delta}$ & $\begin{array}{l}\text { High Fuel Price and } \\
\text { Environmental Awareness } \\
\text { (HFP_HEA) }\end{array}$ & 2124 & 500 \\
\hline
\end{tabular}

Table 2. Environmental taxation and fuel price scenarios considered

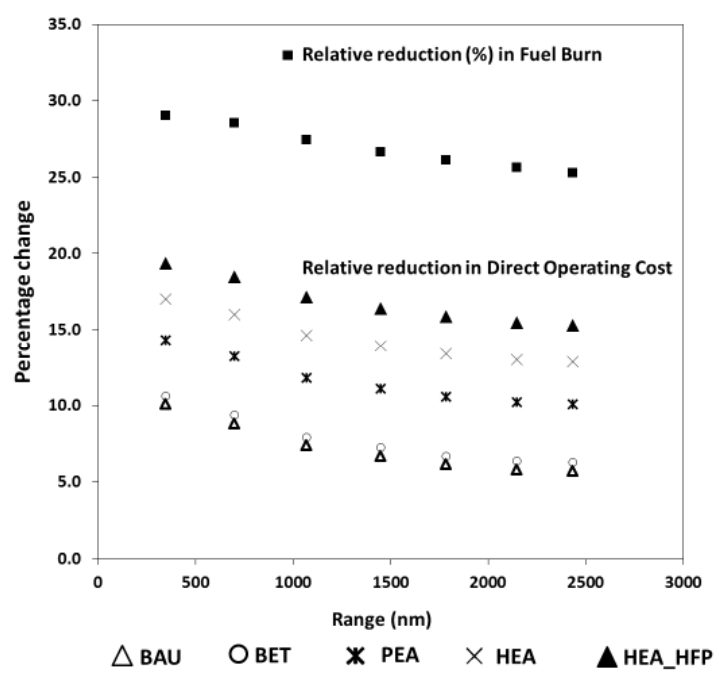

Fig. 10 Relative fuel burn and operating costs for representative missions under various emission taxation and fuel price scenarios (CROR vs conventional TF aircraft)

The improvement in operating cost for the BAU scenario is lower than the fuel consumption improvement, and varies from $5.5 \%$ to $10 \%$ for increasing range. This difference is attributed to the influence of time, fuel and emissions in the calculation of cost. In the BAU scenario the increased influence of the time dependent costs, coupled with the slight increase in block time for the CROR aircraft result in a lower impact of the fuel benefits on the operating cost. As the emission taxation and fuel price increase, the effect of fuel dependant costs increases and consequently the DOC benefit improves. For example, as shown in Fig. 10, in a HEA_HFP scenario the operating cost benefit has increased relative to the BAU scenario and now ranges from $15 \%$ to $19 \%$. It has to be noted here that the DOC savings predicted for the BAU scenario are again in agreement with the figures reported in the literature (Rohrbach, 1976), a fact that strengthens the confidence in the conducted modelling. 


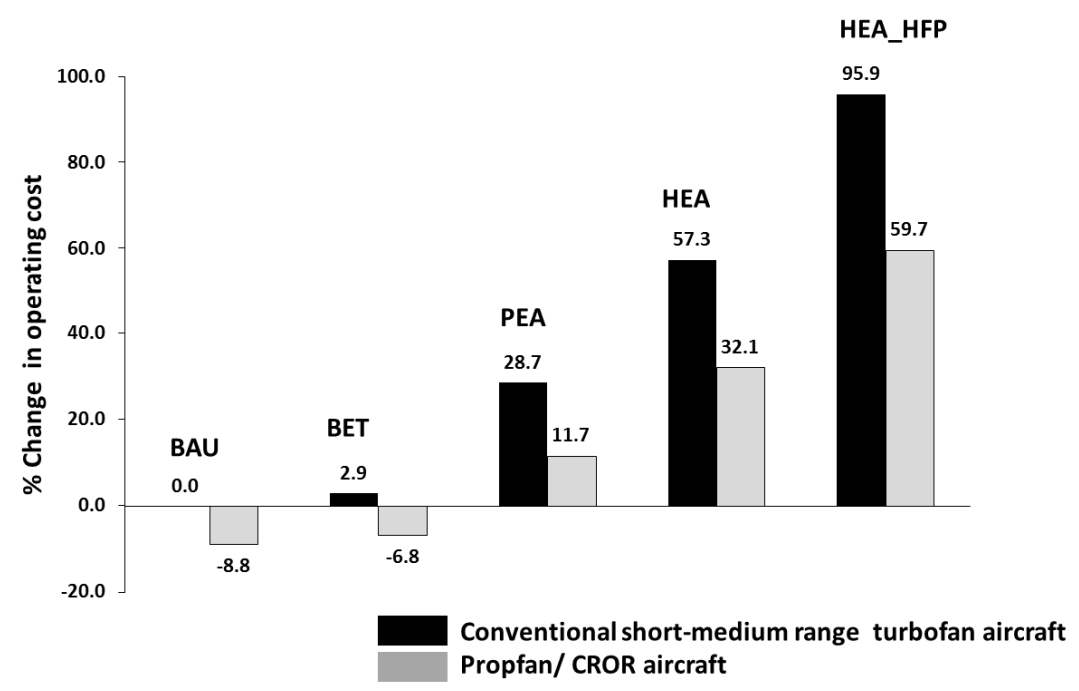

Fig. 11 Variation in operating cost for scenarios, relative to the operating cost of the conventional HBPR aircraft in the BAU scenario, for a $697 \mathrm{~nm}$ mission.

The benefits of the technology are further highlighted if the revenue potential of the technology is considered under higher taxation scenarios. As an illustrative example, the $697 \mathrm{~nm}$ mission is considered.

Fig. 11 shows the increase in operating cost of both technological solutions, for the different economic scenarios, relative to the operating cost of the conventional TF aircraft in the BAU scenario. This comparison demonstrates the effect different taxation and fuel price scenarios will have on the operating cost of both technologies when compared with the BAU scenario. It is observed that in a scenario of higher environmental awareness or fuel shortage, the operating cost of the conventional TF aircraft might increase up to $96 \%$ relative to the BAU baseline scenario. This would have an immediate and considerable negative impact on ticket prices. Although the CROR aircraft operating cost increases too, it is still $9 \%$ to $35 \%$ cheaper to operate. Hence such a scenario would render the CROR aircraft an attractive and economical option, and helps keep the civil air transport business on a sustainable path.

\subsection{Investment cost analysis approach}

The promising potential of reducing the fuel burn and operating cost by using the CROR concept has been demonstrated in the previous section.

However the operating cost calculated, was made under the assumption that the acquisition and maintenance cost for both technologies under consideration are equal. This section, through illustrated cases, examines the effect of increasing these costs on the operating cost benefit demonstrated in the previous section.

The investment cost analysis module is utilised for producing the operating cost data used in the contours shown in Figs. 13, 15 and 16, for different emission taxation and fuel price scenarios. The Weighted Average Cost of Capital (WACC) for all cases considered is assumed to be $7 \%$ (Dray and Morrell, 2009). The shaded area and the plotted area above it, on each plot, indicates the nonfeasible investment region, in which the IRR was found to be less than or equal to $7 \%$.

Two cases are considered to examine the sensitivity of the operating cost reduction. In the first case the effect of relative changes in acquisition and maintenance cost are analysed for a set of missions 
of varying ranges, under a HEA_HFP scenario. In the second case the effect of a relative increase in acquisition cost (by 12.5\%) for a short-range mission is analysed, under varying emission taxation and fuel price scenarios.

\section{Case study 1: Effect of mission range on the operating cost benefit for the HEA_HFP scenario.}

The first case considers the effect of the mission range on the operating cost benefit for an extreme environmental scenario (HEA HFP- Fuel price and carbon tax assumed at US\$2124/ mt and US\$ $500 /$ ton $\mathrm{CO}_{2}$ emission respectively). Three missions with corresponding ranges of 1450, 2433 and 697 $\mathrm{nm}$ have been considered for this case study and for ease of reference, they have been illustrated again in Fig. 12. The investment cost analysis module is utilised for producing the operating cost contours for the three missions (as shown in Figs. 13, 15 and 16 respectively). The shaded area and the plotted area indicate in each figure the non-feasible investment region, in which the IRR was found to be less than or equal to $7 \%$. In order to illustrate the effect of increase in acquisition cost and maintenance cost, for each of three missions, three sub-cases are considered and are superimposed as points in these figures:

Sub-case A: Assumes $20 \%$ increase in acquisition and maintenance cost.

Sub-case B: $35 \%$ and $40 \%$ increase in acquisition and maintenance cost respectively.

Sub-case C: $45 \%$ and $10 \%$ increase in acquisition and maintenance cost respectively.

First considering the $1450 \mathrm{~nm}$ mission, Fig. 13 illustrates the effect of increasing acquisition and maintenance cost on the operating cost, for the HEA_HFP scenario. The operating cost advantage at the datum (refers to $0-0$ in Fig. 13 ) is $16.4 \%$, as calculated previously by the operating cost module and illustrated in Fig.10 and 12.

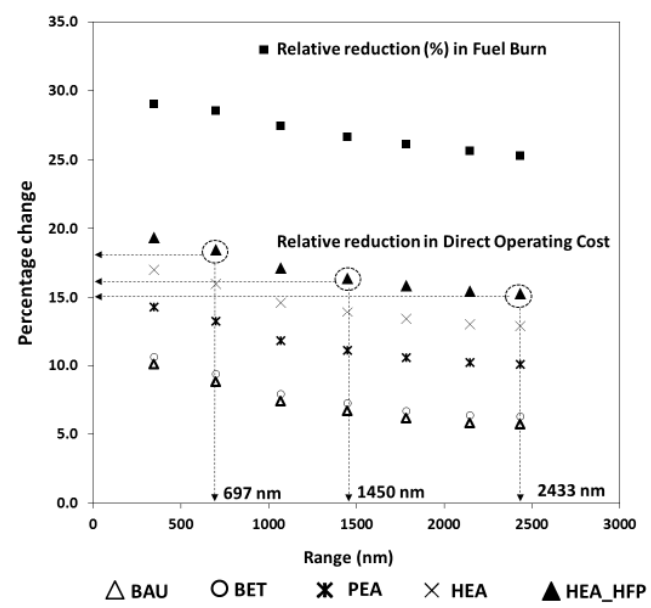

Fig. 12 Illustration of Case 1 missions 


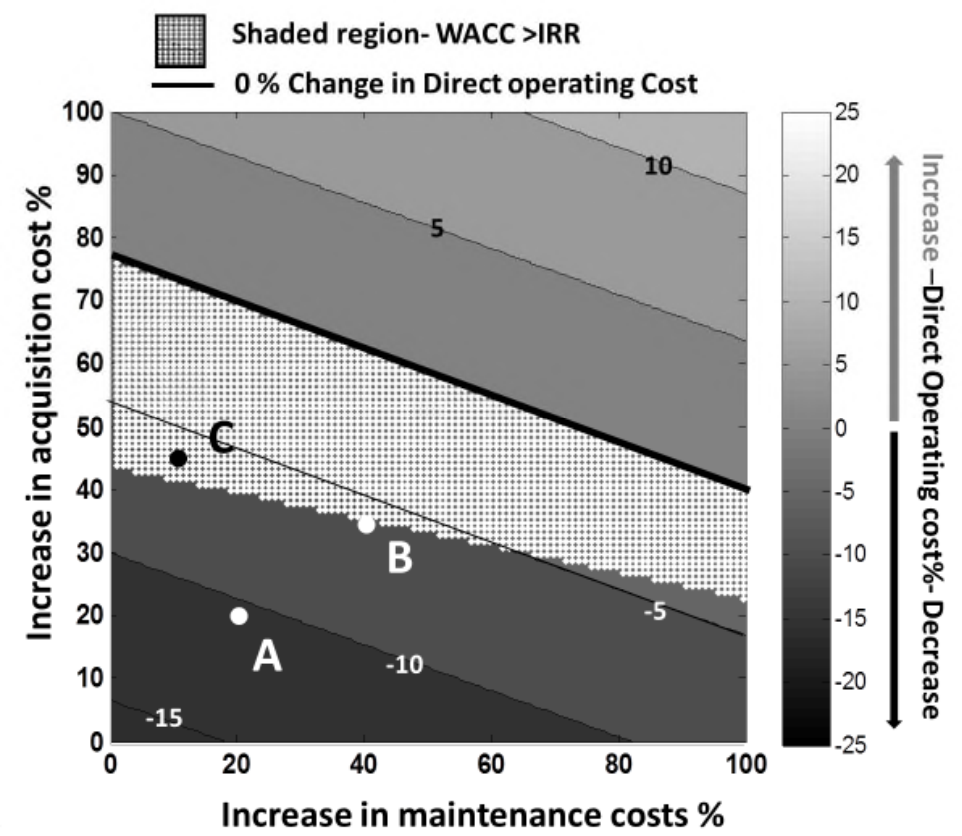

Fig. 13 Investment cost analysis contour (mission range- $1450 \mathrm{~nm}$, Scenario- HEA_HFP, DOC\% benefit at datum $16.4 \%$ )

For the three sub cases of this mission, the NPV is plotted against the discount rate (Fig. 14) using the described procedure. The IRR values calculated for each of the three sub-cases are $30.9 \%, 7.4 \%$ and $4.7 \%$ respectively. Based on these values and on Fig. 13, the following observations can be made:

- The direct operating cost benefit of sub-case A $(20 \%$ increase in acquisition and maintenance cost) has been reduced to $10.6 \%$ from the datum value of $16.4 \%$ due to the increased maintenance and acquisition costs. However, the technology is still profitable as the IRR is $30.9 \%$, which is greater than the assumed WACC of $7 \%$ which leads to the point A lying outside the shaded non-feasible area in Fig. 13.

- In sub-case B (35\% and $40 \%$ increase in acquisition and maintenance cost respectively) the direct operating cost improvement has dropped to $5.8 \%$ but the technology is still just profitable (lying outside the border of shaded non-feasible area) with an IRR of $7.4 \%$.

- In the high acquisition and low maintenance cost sub-case C (Fig. 13) the DOC benefit (6.0\%) is actually $0.2 \%$ higher than sub-case B. However the IRR is lower than required (4.7\%) and the point falls inside the shaded region of (marked as black dot in Fig. 13). This happens because the increased acquisition cost is a current cost incurred when the aircraft is purchased, contrary to the direct operating cost benefits, which come as annual cash flows throughout the lifespan of the aircraft and thus have a lower present value. 


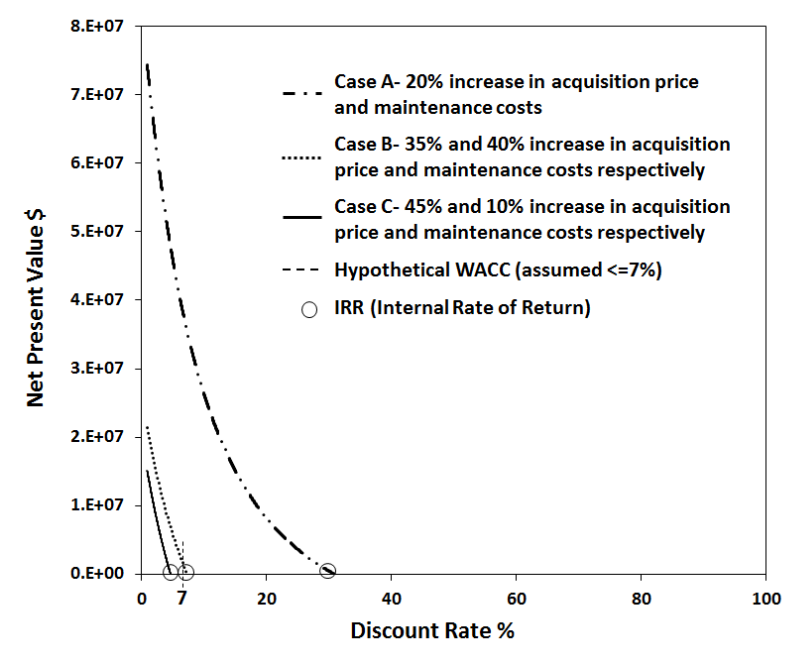

Fig. 14 Verification of IRR calculation- NPV vs Discount rate curves

The case study shows that in order to translate the reduction in fuel burn to a benefit in operating cost and most importantly, to an adequate IRR, the relative change in acquisition price and maintenance costs should be low. The acquisition cost seems to have a greater impact, mainly because it is a cost incurred today.

For the three sub-cases, when considered for a longer range of $2433 \mathrm{~nm}$ (contour plot in Fig. 15) and under the same environmental taxation scenario(HEA_HFP), it is observed that sub-cases B and C, even though profitable in terms of operating cost, are in the non-feasible investment region (marked as black dots Fig. 15). However for the three sub-cases, when considered for a shorter range of 697 $\mathrm{nm}$ case under the same scenario, it is observed that for sub-case $\mathrm{A}, \mathrm{B}$ and $\mathrm{C}$, are all profitable in terms of operating cost, and are all within the feasible investment region (Fig. 16). This observation is further illustrated when the IRR for the sub- cases are plotted against the mission range (Fig. 17), where it is clearly seen that an increase in range decreases the achieved IRR.

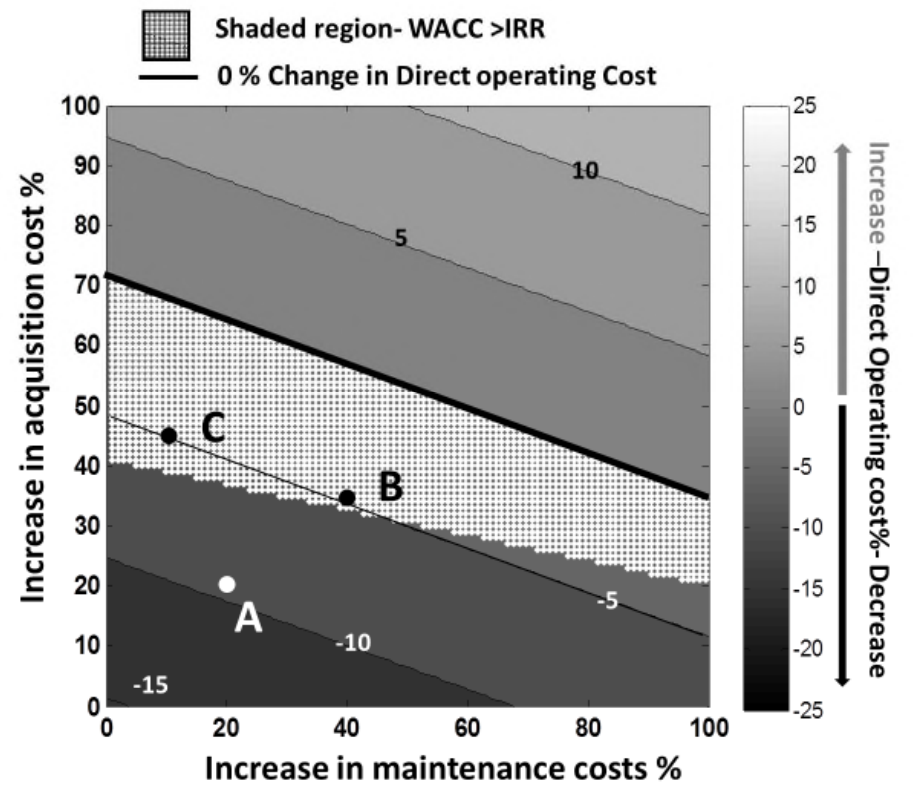

Fig. 15 Investment cost analysis contour (mission range- $2433 \mathrm{~nm}$, Scenario- HEA_HFP, DOC\% benefit at datum $15.3 \%$ ) 
This observation may be explained by referring back to Fig. 12. The technology is best suited for shorter ranges as the relative reduction in fuel burn is higher and time penalty is lower and hence produces a relatively higher improvement in operating cost. With an increase in relative acquisition price and maintenance costs (as demonstrated in Case $\mathrm{B}$ and $\mathrm{C}$ ) longer range missions become unprofitable (Fig. 17).

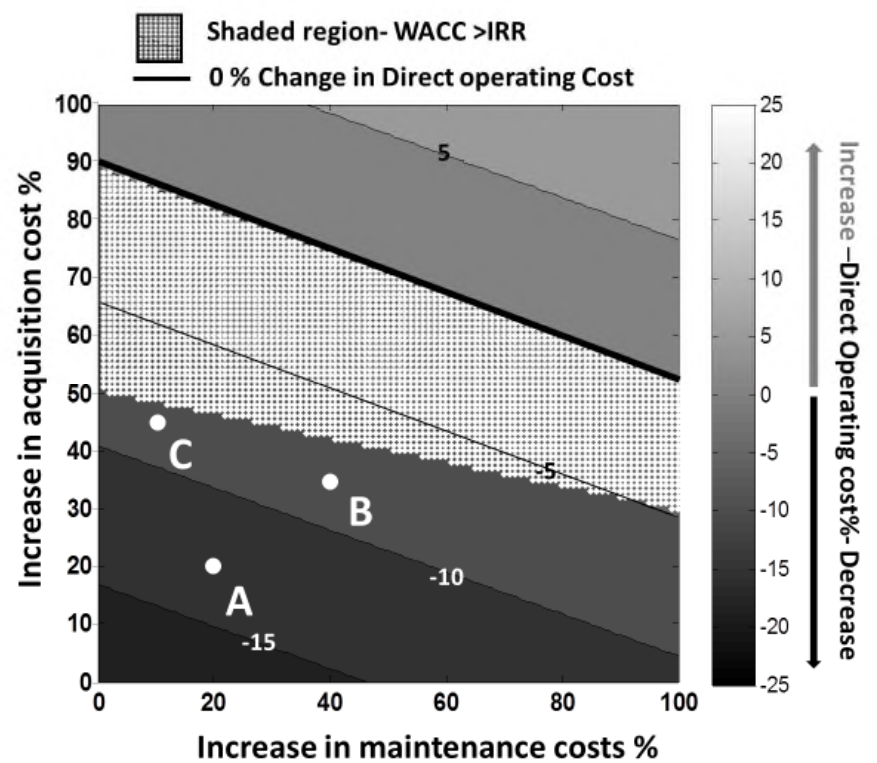

Fig. 16 Investment cost analysis contour (mission range- $697 \mathrm{~nm}$, Scenario- HEA_HFP, DOC\% benefit at datum 18.5\%)

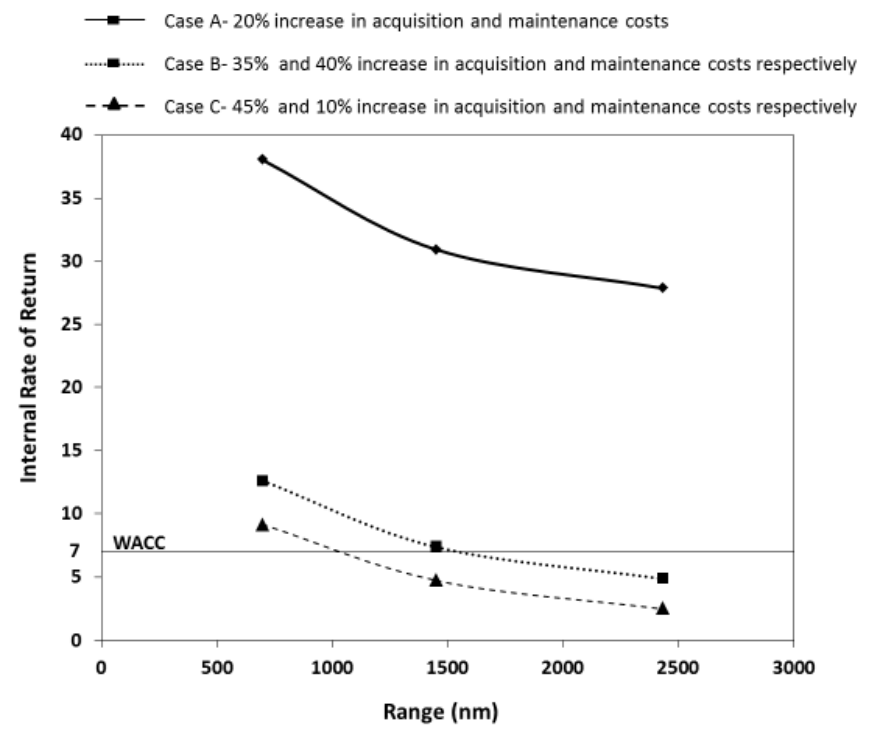

Fig. 17 IRR analysis for various mission ranges

Case study 2: Effect of an increase in acquisition cost for a $697 \mathrm{~nm}$ mission, under varying emission taxation and fuel price scenarios.

Having established the higher benefit of the technology when applied to shorter ranges the next case examines the effect of an increase in acquisition cost for a $697 \mathrm{~nm}$ mission, under varying emission taxation and fuel price scenarios. For illustrative purposes the study assumes an increase of $12.5 \%$. 
The fuel benefit accrued from using the CROR aircraft for the $697 \mathrm{~nm}$ mission is shown to be $28.6 \%$ with an increase in time of $3.6 \%$ (Table 1). The DOC/IRR contour plots are created for the five scenarios as seen in table 2 (Figs. 18-22). For the selected increase in acquisition cost (12.5\%), Fig. 23 separately shows the effect an increase in maintenance cost will have on the IRR.

In a BAU scenario with no increase in acquisition and maintenance cost, the cost contour shows a benefit of $8.8 \%$ in operating cost at the datum (Fig. 18). If the acquisition cost were to increase by $12.5 \%$, with no increase in maintenance cost, the benefit in operating cost will drop to $3.7 \%$. Furthermore, as seen in Fig. 18 the point now lies in the non-feasible investment region as the IRR $(6.4 \%)$ is lesser than WACC (may also be further seen in Fig. 23)

If this case were now to be considered under the BET taxation scenario, the cost contour (Fig. 19) shows an improvement of $9.4 \%$ in operating cost at the datum. With an increase in acquisition cost of $12.5 \%$, the operating cost benefit would decrease to $4.4 \%$, which is slightly higher than the BAU scenario for the same condition. On the other hand, the impact of the BET scenario on the IRR will be much higher, which is now equal to $9.1 \%$. The solution therefore lies outside the shaded region and hence makes it a feasible investment option.

If according to the PEA, HEA and HEA_HFP scenarios, the taxation and fuel price were to further increase, the benefits in operating cost would go up to $9.6 \%, 12.8 \%$ and $15.9 \%$ respectively, for the $12.5 \%$ increased acquisition cost case (Figs. 20-22).

This case study indicates that with the current fuel price and with no emission taxation (BAU scenario), a higher relative acquisition price (of $12.5 \%$ ) will negate the fuel burn advantage of the CROR aircraft. This effect becomes more pronounced with a relative increase in maintenance costs. Therefore, an increase in acquisition price and maintenance cost will then necessitate a high level of taxation and/or fuel price (PEA, HEA and HEA_HFP scenarios) to translate the benefits of reduced fuel burn to operating costs and thus render the CROR technology economically viable.

If the focus now turns to the maintenance cost effect, the following comments can be made. As the acquisition cost increases, the maximum maintenance cost that still gives a solution in the feasible region falls. This means that engines with lower acquisition cost are allowed to have a much higher maintenance cost before they become unprofitable. Furthermore, Fig. 23 indicates that as the emission taxation and fuel price increase, the effect of maintenance cost on the profitability reduces. From the PEA, HEA and HEA_HFP scenario contours (Figs. 20-22) it is observed that if the acquisition cost increase is below $3 \%, 12.2 \%$ and $30 \%$ for the three scenarios respectively, then even with a $100 \%$ increase in the relative maintenance costs, the operating cost benefit decreases, but still remains profitable (IRR remains greater than WACC). This may have an important implication on the engine design. Under these scenarios engine designs could be optimised for very high fuel efficiency and low emissions, by sacrificing engine life and accepting an increase in maintenance costs. Nevertheless, such a trade-off is unlikely to be popular with airlines; it would increase the complexity of fleet operations and result in increased acquisition costs due to the need for more spare engines. 


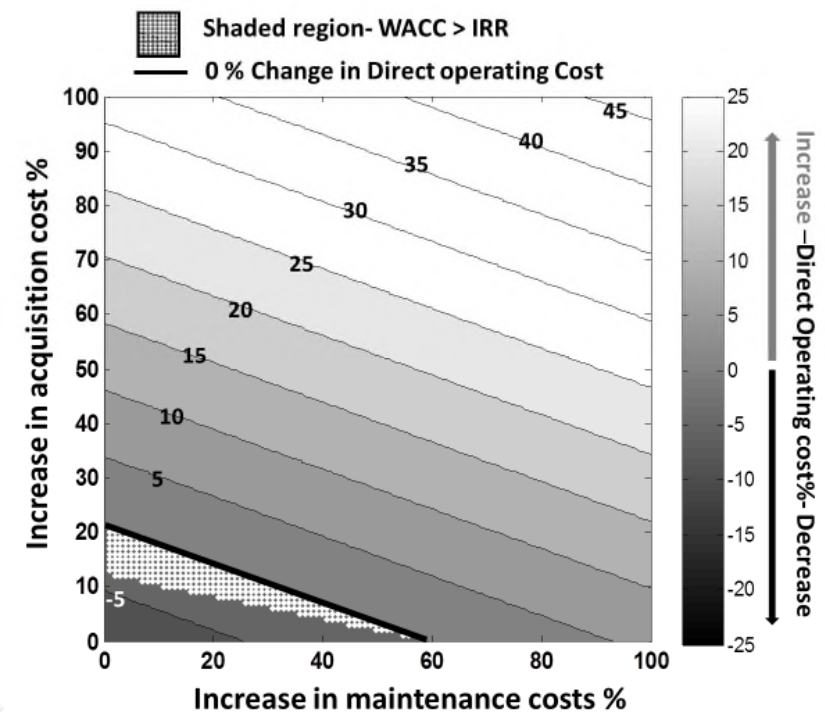

Fig. 18 Investment cost analysis contour (mission range- $697 \mathrm{~nm}$, scenario- BAU, DOC\% benefit at datum $8.8 \%$ )

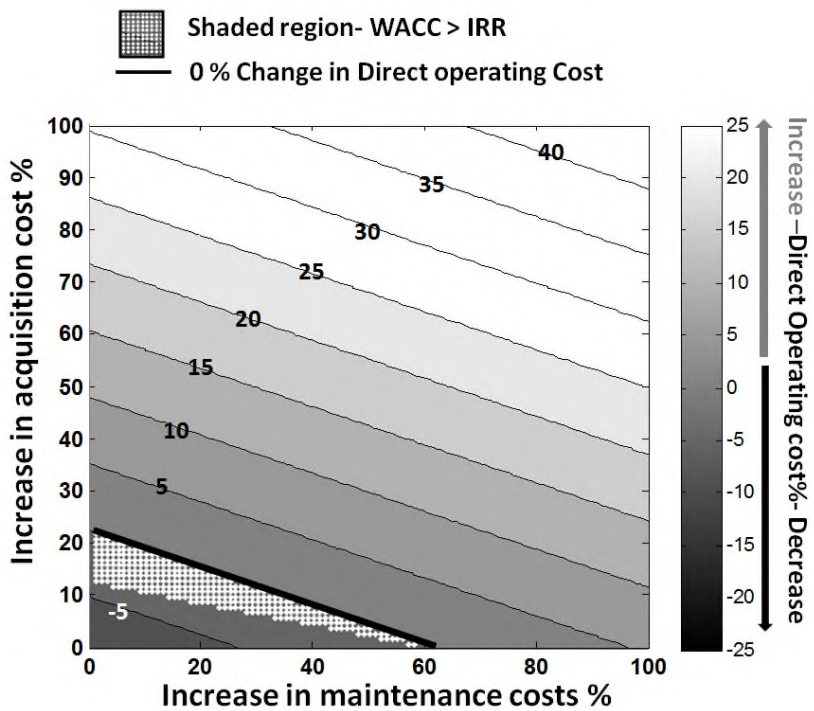

Fig. 19 Investment cost analysis contour (mission range- $697 \mathrm{~nm}$, scenario- BET, DOC\% benefit at datum $9.4 \%$ ) 


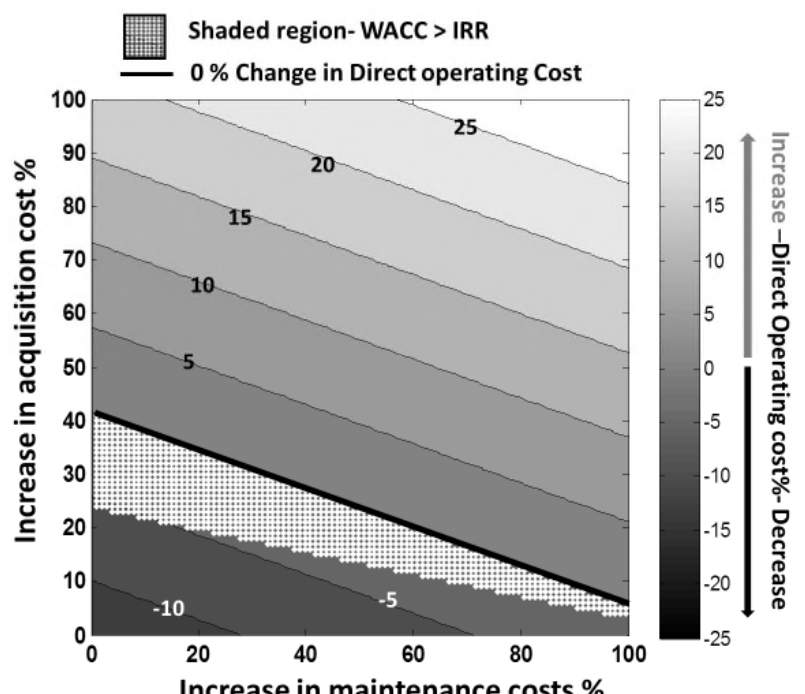

Fig. 20 Investment cost analysis contour (mission range- $697 \mathrm{~nm}$, scenario- PEA, DOC\% benefit at datum $13.2 \%)$

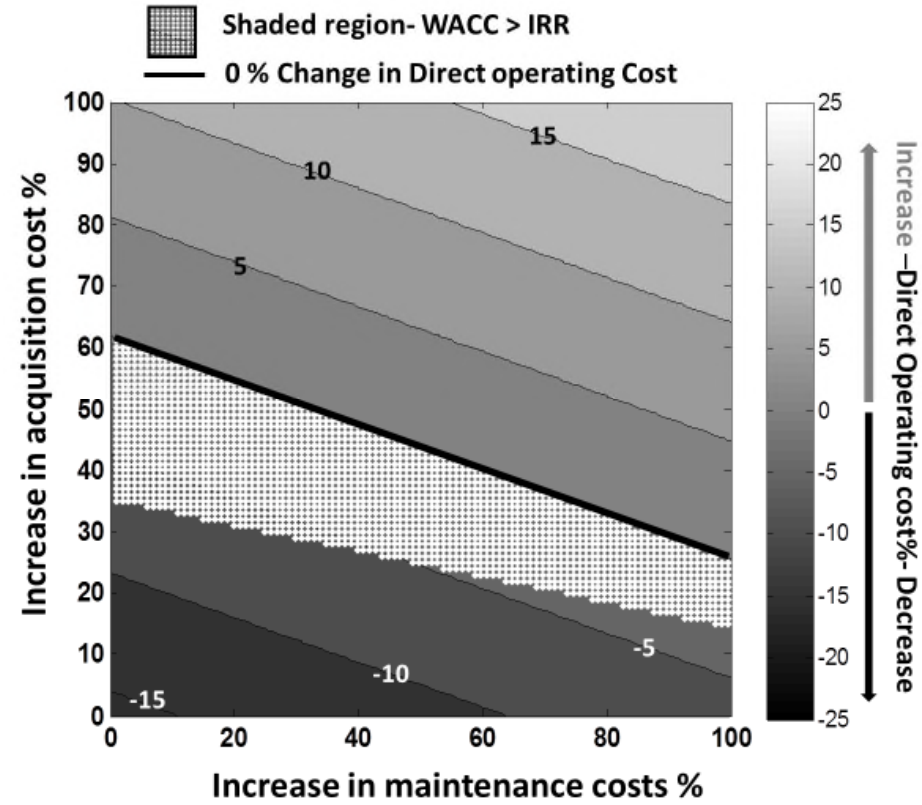

Fig. 21 Investment cost analysis contour (mission range- $697 \mathrm{~nm}$, scenario - HEA, DOC\% benefit at datum $16 \%)$ 


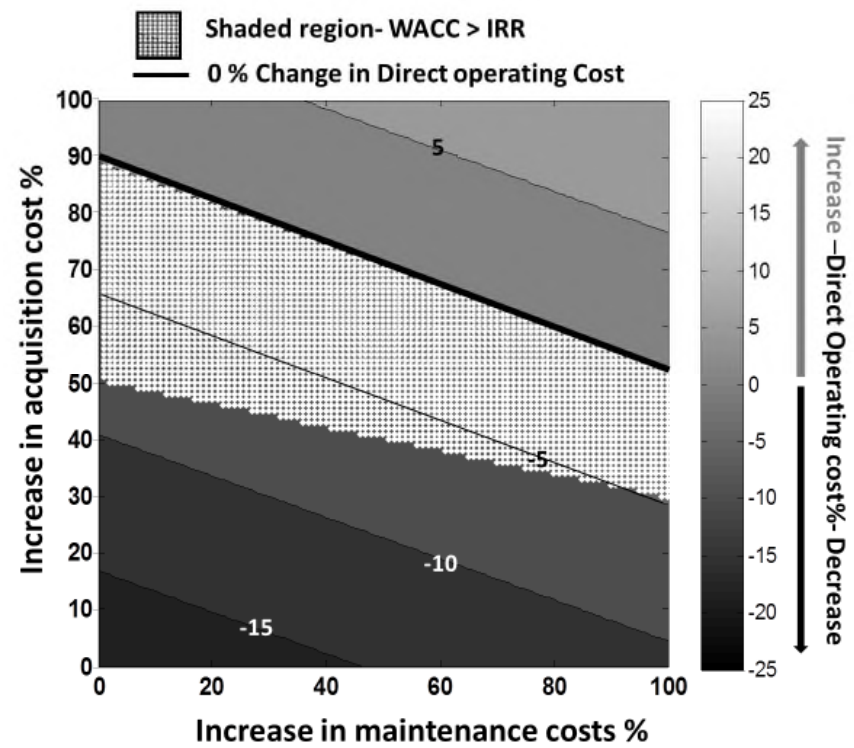

Fig. 22 Investment cost analysis contour (mission range- $697 \mathrm{~nm}$, scenario- HEA_HFP, DOC\% benefit at datum $18.5 \%$ )

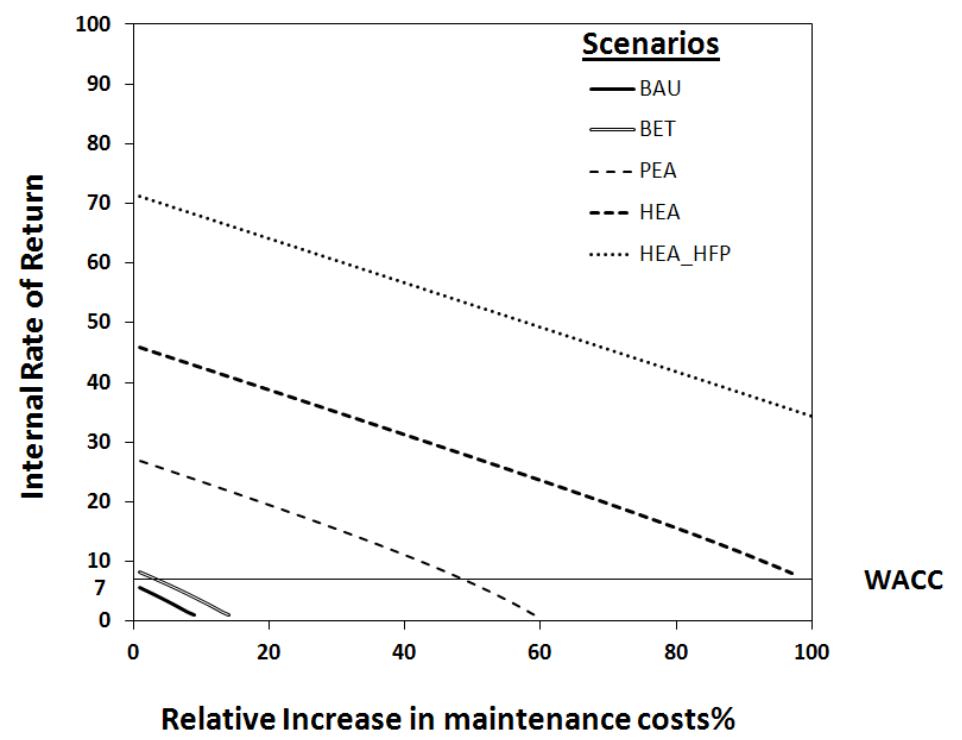

Fig. 23 Effect of maintenance cost on IRR for different scenarios and a case of $12.5 \%$ increase in acquisition price (mission range: $697 \mathrm{~nm}$ )

\subsection{Conclusion}

A methodology has been presented to assess and forecast the viability of a new technology, relative to a conventional technology in civil aviation. Using a Techno-economic Environmental Risk Assessment framework, the methodology enables the user to select energy efficient optimised configurations aimed primarily at mitigation of environmental pollutants. It first establishes the benefits of the novel concept in terms of performance and energy efficiency and further goes on to examine and compare various emission taxation and fuel price scenarios. Additionally by assessing the sensitivity of operating cost to relative increases in acquisition price and maintenance costs, the methodology aims to enable the user to establish the economic viability of a conceptual technology. A proof of concept of this methodology has been demonstrated by assessing the viability of the Counter Rotating Open Rotor aircraft as a competitor to a short to medium range conventional turbofan aircraft. The payload-range performance and energy efficiency assessments initially establish the 
suitability of the novel technology. The study then simulates the performance of the aircraft for a set of typical short to medium range missions.

The Counter Rotating Open Rotor concept, by virtue of high propulsive efficiency, has been proven to reduce fuel burn in comparison to a conventional turbofan aircraft. This effect is demonstrated over the set of missions chosen, by the relative reduction in fuel burn which ranged from $25.3 \%$ to $29 \%$.

When the fuel burn was translated to operating costs for the simulated missions, it resulted in a much lower relative benefit in terms of cost, ranging from $5.7 \%$ to $10 \%$, for an assumed fuel price (1062 $\$ / M T$ ) and in the absence of environmental tax environmental tax scenario.

The operating cost benefit was established based on the assumption that the acquisition price and the maintenance costs of both conventional and novel technologies were equal. However, the investment analysis module has been utilised to further assess the sustainability of the economic benefit demonstrated, under the effect of relative increases in acquisition and maintenance costs. Some of the key observations are as follows:

- In order to translate the reduction in fuel burn to a benefit in operating cost the relative change in acquisition price and maintenance costs should be low for all scenarios.

- In short-range missions the profitability of the CROR concept is more resistant to increases in acquisition price and maintenance cost, as the fuel benefits are higher in that case.

- Based on the modelling assumptions, at the current fuel price and with no emission taxation (BAU scenario), a higher relative acquisition price increase (of 12.5\%) will negate the fuel burn advantage of the CROR aircraft. This effect becomes more pronounced with a parallel increase in the maintenance cost.

- For the high emission taxation and fuel price scenarios (HEA and HEA_HFP) there is limited influence of maintenance costs. This has important implications on engine design. Engines could be designed for high efficiency by sacrificing the engine life and accepting an increase in maintenance costs.

- In the BAU scenario, an increase in relative acquisition price and maintenance cost could make the CROR technology unprofitable, despite its fuel benefits.

As a final conclusion, the present work suggests that if policy makers want to direct industry towards the greener propulsion solution, then an increase in $\mathrm{CO}_{2}$ emission taxation maybe appropriate. Such a policy would make the operation of CROR technology not only economically viable but profitable and hence the preferred option.

\section{Acknowledgements}

We would like to thank Dr Panagiotis Giannakakis and Prof John Fielding for their invaluable help and advice rendered in the technical work undertaken. It would have been impossible to put it together without their guidance.

\section{References}

Aircraft Commerce (2010) Operator's \& Owner's Guide: 737NG family, 2010, Aircraft Commerce, Issue 70 June/July 2010, Nimrod Publications Limited, United Kingdom

Alexiou, A., Roumeliotis, I., Aretakis, N., Tsalavoutas, A., and Mathioudakis, K. (2012) Modeling Contra-Rotating Turbomachinery Components for Engine Performance Simulations: The Geared Turbofan With Contra-Rotating Core Case. ASME J Gas Turb Pwr, 134(11), November. DOI: 10.1115/1.4007197 
ATR (2009) ATR aircraft marketing data (ATR72-210),

$<$ http://www.atr.fr/content/media/downloads/ATR\%204272\%20The\%20Regional\%20Way\%2

$\underline{\text { 02009-light.pdf }}>$ (accessed 02.12.2012)

Bellocq, P., Sethi, V., Cerasi, L., Ahlefelder, S., Singh, R., Tantot, N. (2010) Advanced Open Rotor Performance Modelling for Multidisciplinary Optimization Assessments, In Proceedings of ASME TURBO EXPO 2010, GT2010-22963, doi:10.1115/GT2010-22963.

Boeing (1990) MD 80 Series- Airplane characteristics for airport planning, Boeing Commercial airplanes, Seattle Washington

Boeing (1995) Technical characteristics MD-80 series, < http://www.boeing.com/commercial/md80/product.html > (accessed 02.12.2012)

Boeing (2006) Boeing 737_NG Family Payload Range Summary, <http://www.boeing.com/commercial/startup/pdf/737ng payload.pdf > (accessed 02.12.2012)

Bowles, M. D. and Dawson, V. P.(1998) The advanced turboprop project: Radical innovation in a conservative environment- Chapter 14, From engineering science to big science, National Aeronautics and Space Administration, Washington, D.C., USA.

Camilleri, W., Anselmi, E., Sethi, V., Laskaridis, P., Rolt, A., Cobas, P. (2014) Performance characteristics and optimisation of a geared intercooled reversed flow core engine, Proceedings of the Institution of Mechanical Engineers, Part G: Journal of Aerospace Engineering 0954410014530679, doi: $10.1177 / 0954410014530679$.

Doulgeris, G., Korakianitis, T., Pilidis, P., and Tsoudis, E. (2012). "Techno-economic and environmental risk analysis for advanced marine propulsion systems," Applied Energy, Elsevier, vol. 99(C), pages 1-12

Dray, L., Antony, E., Reynolds, T.G., and Schäfer, A. (2009) A Comparison of Aviation Greenhouse Gas Emission Policies for Europe, 9th AIAA Aviation technology, Integrations and Operations Conference, Hilton Head, South Carolina, 21-23 September 2009.

Dray, L., Morrell, P., (2009) Environmental aspects of fleet turnover, retirement and life cycle, Final report March 2009, Omega, Cranfield University, UK

ESDU (1997) Estimation of Airframe Drag by Summation of Components - Principles and Examples, ESDU-97016, London, United Kingdom, September.

Eshelby, M.E (2009) Aircraft Performance: Theory and Practice, Butterworth Hienemann, Oxford, UK

Fawke, A., and Saravanamuttoo, H. (1971) Digital Computer Methods for Prediction of Gas Turbine Dynamic Response, SAE-710550, pp. 1805-1813, Society of Automotive Engineers, February.

Flight International (2007) What ever happened to the propfans, Flight Global (12 ${ }^{\text {th }}$ June 2007), $<$ http://www.flightglobal.com/news/articles/whatever-happened-to-propfans-214520/,> (accessed 12.05.2012)

GE Aircraft Engines (1987) "Full scale technology demonstration of a modern counte-rrotating unducted fan engine concept, Design report", NASACR-180867, December 1987 
Giannakakis, P. (2013) Design space exploration and performance modelling of advanced turbofan and open-rotor engines (PhD Thesis), Cranfield University, United Kingdom.

Goulos, I., Pachidis, V., Celis, C, D'lppolito, R., Stevens, J. (2010) Simulation Framework Development for Aircraft Mission Analysis, GT2010-23379, Proceedings of GT2010, ASME Turbo Expo 2010, Power for Land, Sea and Air, Glasgow, UK, 2010.

Guynn, M.D., et al., (2011) Initial Assessment of Open Rotor Propulsion Applied to an Advanced Single-Aisle Aircraft, 11th AIAA Aviation Technology, Integration, and Operations (ATIO) Conference, 20 - 22 September 2011, Virginia Beach, VA

Hager, R.D (1987) Full scale technology demonstration of a modern counter rotating unducted fan engine concept, report number: NASA-CR_180867, National Aeronautics and Space Administration (NASA) and GE Aircraft Engines, Cincinnati, Ohio, USA

Henderson, R.P., Martins, J.R.R.A., Perez, R.E. (2012), Aircraft conceptual design for optimal environmental performance, January 2012, volume 116 no. 1175, The Aeronautical Journal, pp. 1-22

$\mathrm{Hu}, \mathrm{Y}, \mathrm{Li}, \mathrm{H}$., and Yan, J. (2012) Techno-economic evaluation of the evaporative gas turbine cycle with different CO2 capture options, Applied Energy, 2012, vol. 89, pages 303-314

IPCC (2007), International Panel on Climate Change Fourth Assessment Report: Climate Change 2007, website: http://www.ipcc.ch/publications and data/ar4/wg3/en/ch3s3-6-2.html (accessed 18.01.2013)

Jenkinson, L. R., Simpkin, P., Rhodes, D. (1999) Civil jet aircraft design,1st edition, Butterworth Heinmann, MA, USA

Jeracki, R. J., Mikkelson, D. C. and Blaha, B. J. (1979) Wind Tunnel Performance of four energy efficient propellers designed for Mach 0.8 cruise, report Number TM-79124, NASA

Kirby, M.R and Mavris, D.N (2001) A Technique for Selecting Emerging Technologies for a Fleet of Commercial Aircraft to Maximize R\&D Investment, SAE Aerospace Congress and Exhibition, Seattle, WA, September 10-13, 2001

Kurzke, J. (2003) Achieving maximum thermal efficiency with the simple gas turbine cycle, In Proceedings of $9^{\text {th }}$ CEAS European Propulsion Forum: "Virtual Engine - A Challenge for Integrated Computer Modelling".

Kyprianidis, K.G., Colmenares Quintero, R., Pascovici, D., Ogaji, S., Pilidis, P., and Kalfas, A. (2008) EVA - A Tool for EnVironmental Assessment of Novel Propulsion Cycles, ASME TURBO EXPO 2008 Proceedings, GT2008-50602.

Kyprianidis, K.G. (2010) Multi-disciplinary Conceptual Design of Future Jet Engine Systems (PhD thesis), Cranfield University, Cranfield, Bedfordshire, United Kingdom.

Kyprianidis, K.G., Grönstedt, T., Ogaji, S., Pilidis, P., and Singh, R. (2011) Assessment of Future Aero-engine Designs with Intercooled and Intercooled Recuperated Cores, ASME Journal of Gas Turbine and Power, 133(1), January. DOI: 10.1115/1.4001982. 
Kyprianidis, K.G., Rolt, A., and Grönstedt, T. (2014) Multidisciplinary Analysis of a Geared Fan Intercooled Core Aero-Engine, ASME Journal of Gas Turbine and Power, 136(1), January. DOI: 10.1115/1.4025244.

Larsson, L., Grönstedt, T., Kyprianidis, K.G. (2011) Conceptual Design and Mission Analysis for a Geared Turbofan and an Open Rotor Configuration., In Proceedings of ASME TURBO EXPO 2011, GT2011-46451, doi: 10.1115/GT2011-46451.

Laskaridis, P. (2004) Performance investigations and systems architectures for the More Electric Aircraft (PhD thesis), Cranfield University, Cranfield, United Kingdom

MacMillan, W. L. (1974) Development of a modular-type computer program for the calculation of gas turbine off-design performance (PhD Thesis) Cranfield University, Cranfield

Mair, A. W., Birdsall, D. L. (1996) Aircraft Performance, Cambridge University Press, Cambridge, United Kingdom

Marinai, L., Probert, D., and Singh, R.(2004) Prospects for aero gas-turbine diagnostics: a review, Applied Energy, 2004, vol. 79, issue 1, pages 109-126

Najafi Saatlou, E., Kyprianidis K.G., Sethi, V., Abu, A.O., Pilidis, P. (2014) On the trade-off between minimum fuel burn and maximum time between overhaul for an intercooled aeroengine, Proceedings of the Institution of Mechanical Engineers, Part G: Journal of Aerospace Engineering 0954410013518509, doi: 10.1177/0954410013518509

Nalianda, D.K. (2012) Impact of environmental taxation policies on civil aviation- A Techno-economic Environmental Risk Assessment (PhD thesis), Cranfield University, Cranfield, United Kingdom

NASA (2014) Technology Readiness Level, available at: http://www.nasa.gov/content/technologyreadiness-level/\#.U5VnI_IdVKY ( accessed 01.06.2014)

Padulo, M. (2009) Computational engineering design under uncertainty: an aircraft conceptual design perspective, (PhD thesis), Cranfield University, Cranfield, United Kingdom.

Pascovici, D.S. , Kyprianidis, K.G., Colmenares, F., Ogaji, S.O.T., Pilidis, P. (2008) Weibull Distributions Applied to Cost and Risk Analysis for Aero Engines, In Proceedings of ASME TURBO EXPO 2008, GT2008-51060 doi:10.1115/GT2008-51060.

Pascovici, D.S (2008) Thermo economic and risk analysis for advanced long-range aero engines, (PhD thesis), Cranfield University, Cranfield, United Kingdom

Poll D.I.A (2009) The optimum aeroplane and beyond, March 2009, volume 113 no. 1140, The Aeronautical Journal, pg 151-164

Raymer, D.P (2006) Aircraft design: A conceptual approach, American Institute of Aeronautics and Astronautics, Reston, Virginia, USA.

Reid, C. (1998) Overview of flight testing of GE aircraft engines UDF engine, AIAA/ASME/SAE/ASEE 24th joint propulsion conference, Boston, Massachusetts, paper number: AIAA-88-3082.

Rohrbach, C. (1976) A report on aerodynamic design and wind tunnel test of a propfan model,AIAA paper no: 76-667, AIAA/SAE 12th Propulsion conference, July 26-29,1976, Palo Alto, California, USA. 
Sibilli, T. (2012) Modelling the aerodynamics of propulsive system integration at cruise and high-lift conditions (PhD Thesis), Cranfield University, Cranfield.

Stefko, G. L., Bober, L. J and Neumann, H. E. (1983) New Test Techniques and Analytical Procedures for Understanding the Behaviour of Advanced Propellers, Report number TM-83360, NASA.

Vera-Morales,M., Graham,W., Hall, C., and Schäfer, A.(2008) Techno-Economic Analysis of Aircraft ,Report number FP7-TPT-2008-RTD-1, Deliverable D5 (WP 2 report), TOSCA (Technology Opportunities and Strategies towards Climate friendly trAnsport ) Project, Available at http://www.toscaproject.org/FinalReports/TOSCA WP2 Aircraft.pdf (Accessed on 01.06.2014)

Walsh, P., and Fletcher, P. (1998) Gas Turbine Performance, 1st ed. Blackwell Science, Chichester, United Kingdom.

Xu, L., Kyprianidis, K.G., and Grönstedt, T. (2013) Optimization Study of an Intercooled Recuperated Aero-Engine, AIAA Journal of Propulsion and Power, 29(2), March-April. DOI: 10.2514/1.B34594. 


\title{
Techno-economic viability assessments of greener propulsion technology under
} potential environmental regulatory policy scenarios

\author{
Nalianda, Devaiah
}

Elsevier

Nalianda D, Kyprianidis K, Sethi V, Singh R. (2015) Techno-economic viability assessments of greener propulsion technology under potential environmental regulatory policy scenarios.

Applied Energy, Volume 157, November 2015, pp. 35-50

https://doi.org/10.1016/j.apenergy.2015.07.017

Downloaded from Cranfield Library Services E-Repository 